\title{
Avaliação do Uso de Praças em Áreas de Interesse Turístico: o caso do Centro Histórico de Belém, Pará
}

\section{Evaluation of the Use of Squares in Tourist Interest Areas: the case study of Historical Center of Belém, Pará}

\author{
Marco Aurélio Arbage Lobo ${ }^{1}$ \\ Helena Lúcia Zagury Tourinho ${ }^{2}$ \\ Roseane Lima Coelho ${ }^{3}$
}

\begin{abstract}
RESUMO - As praças desempenham papel social importante nas cidades como locais de lazer, encontros e outras atividades. Aquelas situadas em centros históricos possuem, comumente, elementos de grande valor simbólico e, por isso, despertam grande interesse em serem visitadas por turistas. Para torná-las mais atrativas, é necessário que sejam intensamente usadas, especialmente pelos moradores do entorno, pois assim aumenta-se a segurança desses locais e proporciona aos turistas maiores oportunidades de contato com a cultura local. $\mathrm{O}$ objetivo deste trabalho foi avaliar a capacidade que possuem as praças situadas no Centro Histórico de Belém (CHB) para atraírem os moradores da sua vizinhança. Para isso, propõe a construção do Índice de Atratividade de Praças, composto por fatores considerados relevantes na decisão desses moradores de usar ou não esses locais. $\mathrm{O}$ índice foi testado por meio de um estudo comparativo de cinco praças situadas no CHB. Os componentes do índice de cada praça foram pontuados mediante avaliação técnica em campo e, em seguida, calcularam-se suas notas finais. Essas notas foram testadas por meio de entrevistas com 35 moradores do entorno. As praças mais frequentadas pelos entrevistados foram justamente aquelas com as maiores pontuações no índice. Os resultados mostraram que o índice proposto pode ser um instrumento válido para avaliar a capacidade de uma praça de estimular seu uso pelos moradores, o que constitui um atrativo a mais para serem visitadas por turistas.
\end{abstract}

Palavras-chave: Turismo; Praça pública; Centro histórico; Lazer urbano.

\footnotetext{
${ }^{1}$ Bacharelado em Arquitetura e Urbanismo pela Universidade Federal do Pará (UFPA). Mestrado em Planejamento do Desenvolvimento pela UFPA. Doutorado em Desenvolvimento Socioambiental pela UFPA. Professor e Pesquisador do Programa de Pós-graduação em Desenvolvimento e Meio Ambiente Urbano da Universidade da Amazônia. E-mail: lobo2502@hotmail.com

2 Bacharelado em Arquitetura e Urbanismo pela Universidade Federal do Pará (UFPA). Mestrado em Planejamento do Desenvolvimento pela UFPA. Doutorado em Desenvolvimento Urbano pela Universidade Federal de Pernambuco (UFPE). Professora e Pesquisadora do Programa de Pós-graduação em Desenvolvimento e Meio Ambiente Urbano da Universidade da Amazônia. E-mail: helenazt@uol.com.br

${ }^{3}$ Bacharelado em Educação Artística pela Universidade da Amazônia. Mestrado em Desenvolvimento e Meio Ambiente Urbano pela Universidade da Amazônia. Professora da Secretaria Municipal de Educação de Belém. E-mail: anizcoelho@gmail.com
} 


\begin{abstract}
Public squares have an important social role in the cities as places of leisure, meetings and other activities. Those located in historic centers commonly have elements of great symbolic value and, therefore, they arouse great interest in being visited by tourists. In order to make these spaces more attractive, they need to be intensively used, especially by the surrounding residents, because the safety can be increased in these places and can provide to the tourists greater opportunities for contact with the local culture. The aim of this work was to evaluate the capacity of the squares located in the Historic Center of Belém do Pará, Brazil (CHB) to attract the residents and the neighborhood. For this, it was proposed the construction of the Square Attractiveness Index, composed by factors considered relevant in the decision of these residents in using or not these places. The index was tested by a comparative study of five squares located in the CHB. The index components of each square were scored by technical evaluation in a field study and then the final grades were calculated. These grades were tested with 35 interviews with surrounding residents. The squares most frequented by the respondents were precisely those with the highest scores in the index. The results showed that the proposed index might be a valid instrument to evaluate the capacity of a square to stimulate its use by residents, which is an additional attraction for tourists to visit.
\end{abstract}

Keywords: Tourism; Public square; Historical center; Urban leisure. 


\section{INTRODUÇÃ̃O}

Os lugares de interesse histórico e cultural constituem um dos mais importantes recursos para o desenvolvimento do turismo de um local (ISMAGILOVA; SAFIULLIN; GAFUROV, 2015). Nesse contexto, as praças situadas em áreas históricas ganham especial destaque, considerando que esses locais normalmente atraem moradores do lugar, o que constitui uma oportunidade para que os turistas entrem em contato com os residentes. Por outro lado, isso é bem visto pelos moradores, conforme salientam Machado e Alves (2013) ao estudarem como moradores de Ouro Preto (MG) percebem a atividade turística.

Os valores históricos e culturais - e, modernamente, turístico - das praças, enquanto portadores da memória coletiva da urbe, justificam a necessidade de preservar e valorizar esses lugares (ROSSI, 2001). Para Argan (2005), a recuperação da memória da cidade antiga é um contraponto necessário à ênfase excessiva na funcionalidade da cidade moderna, sendo algo importante para integrar ambas as partes. Contudo, a conservação e, consequentemente, seu potencial turístico, relaciona-se, em grande medida, à utilização que é dada pela população ao patrimônio construído. Nesse contexto, assumem importância aspectos como atratividade, funcionalidade, acessibilidade, eficiência, segurança, paisagismo e conforto ambiental que as praças possam oferecer aos seus usuários, moradores, trabalhadores e turistas.

Do exposto emerge, então, a seguinte questão: na atualidade, qual a capacidade que possuem as praças situadas em áreas históricas e de interesse turístico das cidades brasileiras para atraírem seus moradores e, dessa forma, constituírem locais movimentados e com oportunidades para interação entre turistas e população local?

O presente artigo aborda essa questão por meio da mensuração e da avaliação do grau de atratividade de praças para moradores do seu entorno. Constrói, para isso, um índice de atratividade composto por fatores considerados relevantes na decisão desses moradores de usar ou não uma praça, por meio de uma análise comparativa de cinco praças situadas no Centro Histórico de Belém (CHB). Tais fatores foram traduzidos em indicadores componentes do índice proposto. 
Para validar o índice, realizaram-se entrevistas com moradores do entorno das praças selecionados aleatoriamente, independentemente de serem usuários ou não desses espaços.

O trabalho empírico foi desenvolvido em cinco praças localizadas no bairro Cidade Velha, o mais antigo dos dois bairros que compõem o CHB: Dom Frei Caetano Brandão, Dom Pedro II, República do Líbano, do Carmo e Filipe Patroni. Além dessas cinco praças, o bairro conta ainda com a Praça do Relógio, que foi excluída do estudo por possuir apenas um relógio, monumento que dá nome ao logradouro.

A escolha desse bairro, parcialmente inserido no CHB (BELÉM, 1994), deu-se por três motivos. Primeiro, por ter sido tombado em 1990 pelo município (BELÉM, 1990) e, posteriormente, pelo Instituto do Patrimônio Histórico, Artístico e Cultural (IPHAN) em 2012, que o considerou como "Conjunto Arquitetônico, Urbanístico e Paisagístico". Segundo, por ter um número significativo de praças com tipologias diversificadas, há várias opções de escolha pelos moradores, o que possibilita a comparação entre elas. Terceiro, por sua importância como local turístico de Belém.

O artigo está estruturado em oito partes. A primeira é esta introdução. A segunda apresenta uma breve evolução do papel e da configuração espacial das praças na cidade brasileira. A terceira expõe aspectos históricos e as características atuais (configuração física e entorno) das praças estudadas. A quarta descreve a concepção e o procedimento de cálculo do Índice de Atratividade de Praças (IAP). A quinta realiza uma discussão dos resultados. E a sexta apresenta as considerações finais. Também há um apêndice que apresenta os componentes do índice.

\section{PRAÇAS NA URBE BRASILEIRA}

As praças desempenharam historicamente papel relevante nas cidades enquanto espaço público de socialização. Para Lamas (1993, p. 102), “a praça é o lugar intencional do encontro, da permanência dos acontecimentos, das práticas sociais, das manifestações de vida urbana e comunitária, do prestígio e das funções estruturantes e arquiteturas significativas". Dessa forma, é um elemento básico do desenho urbano e componente fundamental para vários aspectos da vida social da urbe. Sitte (1992) considerava a praça pública como o elemento central para um planejamento urbano bem-sucedido. 
Robba e Macedo (2003, p. 17) definem as praças como "espaços livres urbanos destinados ao lazer e ao convívio da população, acessíveis aos cidadãos e livres de veículos" e as consideram um dos mais importantes espaços públicos da história da cidade. Já para Segawa (1996, p. 31) a praça é um “espaço ancestral que se confunde com a própria origem do conceito ocidental de cidade". Ademais, a frequência a praças e outros espaços públicos de lazer trazem benefícios à saúde física e mental dos usuários (FRANCIS et al., 2012; KOOSARI; BADLAND; GILES-CORTI, 2013; WOOD et al., 2017). O lazer passivo constitui, então, uma função tradicionalmente presente nas praças, daí se constituir num componente obrigatório em qualquer estudo de avaliação desses espaços públicos, a exemplo do índice proposto no presente trabalho.

Por serem locais com alto potencial de interação social entre moradores e turistas, Zakariya, Harune e Mansor (2015) salientam a necessidade de a adequação física das praças ao interesse turístico não cause prejuízos ao seu uso pela população local.

Nesse contexto, coloca-se um desafio teórico: identificar e avaliar que fatores contribuem para atrair pessoas para usar uma praça ou dissuadir este uso, a exemplo do trabalho realizado por De Angelis, Castro e De Angelis Neto (2004), que serviu como referência inicial para a construção do IAP. Propõe-se, então, três aspectos nesse sentido: as características específicas da praça, de seu entorno e as conexões viárias existentes no local. Outro aspecto de relevante para que uma praça seja usada são os tipos de usos do solo existentes no entorno: se estimulam ou não a movimentação intensa de pedestres no espaço público adjacente a uma praça em horários diversificados, o que aumenta a sensação de segurança e contribui para atrair usuários. A relevância desse aspecto é ressaltada nos trabalhos de Jacobs (2011), Gehl (2013) e Bentley et al. (1999). Justificase, então, a presença deste tema como um dos atributos componentes do IAP. O serviço de policiamento, também presente no indice, é outro aspecto de grande importância para a segurança dos locais públicos.

A despeito da importância das praças, o acelerado crescimento das cidades no Brasil, a partir da década de 1960, e as consequentes dificuldades de gestão urbana vêm repercutindo na quantidade e qualidade dos espaços urbanos. Mudanças nos costumes e nas formas de sociabilidade colocam novos desafios à atratividade dos espaços públicos (CASTRO, 2002; THOMPSON, 2002). Por outro lado, muitas cidades passaram a 
experimentar um processo de degradação do ambiente construído em seus centros históricos, que inclui diversas praças.

Tal degradação está relacionada, no primeiro momento, à mudança de local de moradia das camadas mais abastadas da população, do centro para outras áreas da cidade; e no segundo, ao abandono de centro comercial, por parte dessas mesmas camadas, enquanto local de aquisição de produtos comércio e serviços (VILLAÇA, 2001). O aparecimento de novas centralidades urbanas, concorrentes com os tradicionais centros históricos, também contribuiu para a subutilização do patrimônio construído desses centros e para a sua crescente descaracterização urbanística e arquitetônica. Tudo isso configurou um quadro de degradação física que tem afetado o desempenho das praças enquanto locus privilegiado de convívio social e lazer dos moradores desses centros e de outras partes da cidade.

Os centros históricos são espaços de grande importância cultural no contexto das cidades longevas. Sendo quase sempre o local de origem do tecido urbano, foi onde se instalaram os primeiros portos, prédios administrativos, religiosos e de comércio e serviços da cidade, assim como as primeiras praças e outros espaços públicos relevantes. Por estarem comumente relacionadas a momentos importantes da história das cidades, são espaços de grande valor arquitetônico, simbólico e turístico, além de constituem polos de atração de consumidores, visitantes e moradores de toda a cidade (MEHAN, 2016).

As praças situadas nos centros históricos das cidades brasileiras estiveram associadas ora ao poder religioso, ora ao poder político e econômico. Nesses espaços a população manifestava sua territorialidade, demonstrando sua fé e sua relação com o poder político, o que os converteu em palco de múltiplas manifestações dos hábitos e costumes. Também sofreram importantes transformações em suas funções e configurações físicas ao longo da história, deixando de ser simples largos ou terrenos sem uso para se tornarem praças.

Para Robba e Macedo (2003) o desenvolvimento dos núcleos urbanos coloniais brasileiros era semelhante ao da cidade medieval europeia no que se refere à sua estrutura morfológica. As ruas, os largos e as praças eram configurados a partir da construção do casario, o que resultou em ruas estreitas - e algumas vezes tortuosas - que convergiam para a edificação central do assentamento. Porém, diferiam quanto à função, ao uso e apropriação do espaço livre público, pois os espaços livres nos assentamentos coloniais 
brasileiros apresentavam uma sobreposição de usos quando comparados às funções das praças medievais.

Na primeira fase de formação das cidades coloniais, o modelo da praça religiosa foi o predominante, decorrente da atuação das inúmeras ordens religiosas na Colônia. Com o passar do tempo, essas praças se tornaram o centro vital da cena urbana, com o desenvolvimento de diversas funções em seu espaço (REIS FILHO, 2000; SANTOS, 2001). Nesse período, a praça também foi utilizada pelo Estado como mecanismo de controle no regime escravocrata, com a instalação do pelourinho, onde os condenados eram amarrados e submetidos à execração pública (CALDEIRA, 2010).

O período de transição entre a urbanização colonial e a cidade moderna foi considerado um marco na história dos espaços livres urbanos no Brasil, dentre outros motivos, por alterar a função da praça na cidade. A partir da segunda metade do século XIX, a função do lazer contemplativo nas praças públicas se consolidou e ampliou, sob a influência do novo paradigma de desenho urbano originado na Europa com as reformas de Haussmann em Paris. No Brasil, o discurso higienista da modernização e do embelezamento se traduziu, em algumas cidades, em obras de remodelação de seu centro, a exemplo do que ocorreu no Rio de Janeiro, sob o comando do engenheiro urbanista Pereira Passos (ROBBA; MACEDO, 2003), e em Belém, na administração do Intendente Antônio Lemos (SARGES, 2010).

Em relação às praças, a tônica foi a criação de cenários ajardinados destinados às atividades de recreação e ao lazer contemplativo, especialmente das elites. Nessa fase, vários espaços públicos foram arborizados e urbanizados; os antigos largos descampados remanescentes receberam jardins, bancos, coretos, iluminação e outros elementos. Sofrendo influência ora do paisagismo francês, ora do inglês, ora de ambos, a linha projetual da arquitetura paisagística brasileira nesse período foi denominada eclética. Suas realizações englobam desde os jardins do final do século XVIII até as grandes praças ajardinadas construídas nas primeiras décadas do século $\mathrm{XX}$, e caracterizam-se pela apropriação de vários estilos e influências (ROBBA; MACEDO, 2003).

Referindo-se à cidade de Belém, Sarges (2010, p. 123) salienta que essas praças eram voltadas principalmente para o lazer da elite da época. Constituíam "lugares públicos de lazer e lugar onde todos querem ir para serem vistos. Ser visto é o hobby da 
nova elite. A praça, o lugar onde, com o vestuário se identifica a que classe cada um pertence".

O abandono das elites enquanto moradoras da área central e, posteriormente, como clientes das lojas do centro comercial tradicional, levou essa parcela da população a, gradativamente, deixar de frequentar as praças, por exemplo, do CHB. Ao mesmo tempo, o crescimento e o adensamento populacional tornaram as áreas livres cada vez mais escassas no espaço urbano. Tais fenômenos, associados à popularização das práticas esportivas, tornou as praças uma alternativa cada vez mais popular para o lazer ativo, o que justifica ser este um componente do IAP. Nesse contexto, o modelo dos parques e praças ecléticas, voltado, sobretudo, ao flanar de pessoas de alta renda e a atividades contemplativas, começa a entrar em declínio, já que não atendia mais aos novos requisitos demandados pelo lazer ativo.

A partir da década de 1940, sob a influência de arquitetos paisagistas modernos, surgiram os primeiros sinais de mudança na concepção desses locais da cidade brasileira. Parques e praças passam a englobar, em seu programa, o lazer ativo, especialmente as atividades esportivas e de recreação infantil, deixando de ser projetadas apenas como uma moldura da edificação principal ou como espaço de flanar. Surgem, então, equipamentos como quadra de esporte, brinquedos para recreação das crianças e churrasqueiras (ROBBA; MACEDO, 2003). Essas transformações, contudo, nem sempre puderam ser operadas nas praças de centros históricos, especialmente naquelas que já se encontravam tombadas pelos órgãos do patrimônio histórico.

Outro aspecto importante é a necessidade da adequação dos espaços públicos para garantir a acessibilidade das pessoas deficientes, nos termos da Lei $n^{\circ}$ 10.098/2000 (BRASIL, 2000). Nesse sentido, justifica-se a inclusão de um quesito sobre o assunto no IAP, como forma de averiguar até que ponto as praças são locais atrativos para serem usadas por essas pessoas.

A presença Raskovic e Decker (2015) destacam a influência positiva da presença de árvores na percepção e na permanência de usuários em praças públicas. Por isso, a arborização das praças e, de forma mais ampla, a existência de ambientes agradáveis à permanência dos usuários nesses espaços considerando o clima local, constitui outro componente do IAP. 
Também compõem o índice outros elementos julgados importantes para atrair usuários para as praças, como itens de comodidade e higiene (sanitários públicos, lixeiras e quiosques de alimentação) e serviços públicos de limpeza, varrição promoção de eventos e atendimento social a moradores de rua.

\section{PRAÇAS DO CENTRO HISTÓRICO DE BELÉM (PARÁ)}

A cidade de Belém foi fundada em 1616 como parte dos esforços empreendidos por Portugal para defender o território da colônia contra invasores de outros lugares da Europa. O local escolhido para construir a fortificação que deu origem à cidade situa-se no atual bairro da Cidade Velha. Em 2018, a capital paraense tinha uma população estimada em quase 1,49 milhão pelo IBGE. O fluxo de turistas na capital paraense e municípios vizinhos alcançou 632 mil em 2016 (FAPESPA, 2017). Belém possuiu o 14º aeroporto com maior movimentação de passageiros no Brasil em 2018, com mais de 1,6 milhão de embarques e desembarques (BRASIL, 2019).

O bairro da Cidade Velha, parcialmente situado no Centro Histórico de Belém, contava com uma população de pouco mais de 12 mil habitantes em 2010 (IBGE, 2010), sendo o $37^{\circ}$ mais populoso de Belém. Nesse ano, segundo a mesma fonte, o rendimento domiciliar mediano mensal era de $\mathrm{R} \$ 2.770$, o nono maior do município. As praças do bairro (Figura 1) estão inseridas em uma malha urbana típica do período colonial português, caracterizada por quadras de pequenas dimensões ocupadas com edificações posicionadas no alinhamento das vias, bem como pelas ruas estreitas que apresentam alguma regularidade no traçado. Contudo, a maioria delas ganhou sua atual confirmação em período mais recente, pelas obras de embelezamento da administração do Intendente Antônio Lemos. Foram investigadas cinco praças do Centro Histórico neste trabalho: Frei Caetano Brandão, Carmo, Dom Pedro II, do Carmo, Filipe Patroni, e República do Líbano. A Praça do Relógio, inaugurada em 1931 (SOARES, 2009), possui uma área aproximada de $2.600 \mathrm{~m}^{2}$ e tem como único elemento de destaque o relógio de ferro que lhe dá nome, procedente da Inglaterra; por este motivo, não foi considerada no presente trabalho. 


\section{FIGURA 1: PRAÇAS SELECIONADAS DO CENTRO HISTÓRICO DE BELÉM}

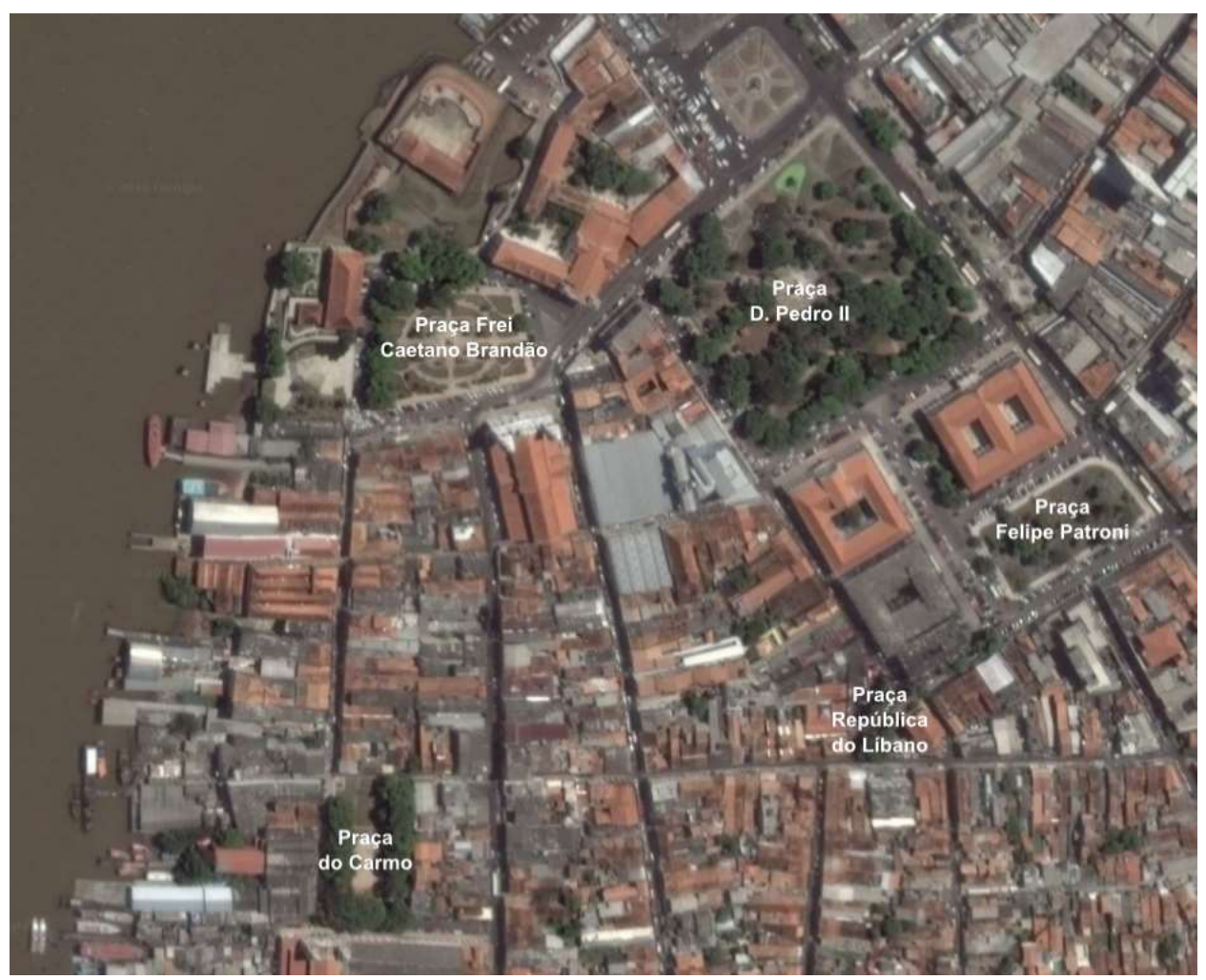

FONTE: Google Earth (2018); Autores. 2018.

A praça Frei Caetano Brandão, antigo largo transformado em praça na administração de Lemos, tem área aproximada de $5.700 \mathrm{~m}^{2}$, possui formato trapezoidal e é a que está mais próxima ao forte que deu origem à cidade de Belém. Concentra no seu entorno um expressivo número de edificações tombadas e de reconhecido valor histórico e artístico, destacando-se o Forte do Presépio (local de fundação de Belém), o Museu de Arte Sacra, a Igreja de Santo Alexandre, a Catedral de Belém e a Casa das Onze Janelas (SOARES, 2009). As edificações religiosas estão relacionadas ao período em que as ordens religiosas detinham grande poder político e econômico. Os usos das edificações localizadas em volta da praça são diversificados, sendo muitos ligados ao lazer e ao turismo. A igreja, os museus, restaurantes e bares, dentre outros usos encontrados funcionam em diversos horários o que garante certa vitalidade à área.

A praça do Carmo constitui uma típica praça de bairro está situada em frente à igreja de mesmo nome. Tem formato retangular e área aproximada de $2.750 \mathrm{~m}^{2}$. Surgiu num local onde foram travadas importantes lutas durante a revolta da Cabanagem. No 
local, podem ser vistas as fundações da antiga Igreja de Nossa Senhora do Rosário dos Homens Brancos (SOARES, 2009). Embora contenha usos de comércio e serviços nas suas bordas, é a que possui, de todas as praças aqui investigadas, o maior número de residências no entorno.

Com as obras de drenagem do igarapé do Piri e o aterramento das suas margens pantanosas, obras concluídas em 1803, foram construídas as praças do Relógio, D. Pedro II e Filipe Patroni. Inaugurada oficialmente em 1882, a praça Dom Pedro II, com uma área próxima a $18.900 \mathrm{~m}^{2}$ (a mais extensa das praças aqui analisadas) e formato retangular, tem em seu entorno prédios institucionais importantes: Prefeitura Municipal de Belém (Palácio Antônio Lemos), Museu do Estado do Pará e Instituto Histórico e Geográfico. Foi objeto de uma reforma no governo de Antônio Lemos no início do século XX com base nos princípios do ecletismo.

A praça Filipe Patroni, denominada inicialmente de Parque Prudente de Moraes, está localizada em terreno situado na parte posterior do Palácio Antônio Lemos (sede oficial da Prefeitura de Belém), tendo cerca de $5.000 \mathrm{~m}^{2}$ de área. Foi um jardim projetado no governo de Antônio José Landi e que, embora inaugurado em 1883, somente em 1908 foi urbanizado (SOARES, 2009). Predominam no seu entorno edificações de caráter institucional, com destaque para a Assembleia Legislativa do Estado do Pará, e estabelecimentos comerciais de pequeno porte.

A praça República do Líbano tem dimensão diminuta (cerca de $500 \mathrm{~m}^{2}$ ) e recebeu essa denominação, em 1978, para homenagear a colônia libanesa que morava nas suas proximidades. É mais conhecida pela população como Largo de São João, por estar situada ao lado de uma capela de mesmo nome - originada de uma antiga ermida (SOARES, 2009). Além da edificação religiosa, destacam-se no seu entorno a Assembleia Legislativa (fundo e parte lateral), uma escola pública e um prédio com atividade do Poder Judiciário. A praça é vizinha à Capela de São João e próxima aos palácios ligados ao poder civil. Por isso, tem o uso do solo de suas imediações influenciado por esses dois conjuntos de atividades.

Ao se considerar os momentos históricos em que as praças estudadas foram estabelecidas, observa-se a estreita relação existente entre as circunstâncias de sua origem e os usos do solo do entorno. A despeito das diversas reformas sofridas ao longo do tempo, a maioria das praças localizadas no CHB permanecem com características 
paisagísticas que não favorecem a prática de lazer ativo. Mesmo reformas mais recentes, a exemplo da realizada nas praças do Carmo na década de 1990, não alteraram essas características.

Ressalte-se que, nas praças do CHB, encontram-se um expressivo contingente de trabalhadores informais (vendedores, engraxates etc.), que, por sua vivência diária nesses locais, acumulam um rico acervo de informações sobre a vida cotidiana dessas praças (SOBRAL, 2006). Esse fato amplia as possibilidades de conhecimento da cultura local por parte dos visitantes.

Diante dessas características das praças do Centro Histórico, na seção seguinte serão expostos os procedimentos para a análise da atratividade das mesmas.

\section{MATERIAIS E MÉTODOS}

Para analisar a atratividade das praças do CHB, adotou-se um procedimento dividido em duas etapas: a) mensuração do grau de atratividade de cada uma das praças estudadas para os usuários do entorno, por meio de avaliação técnica dos aspectos considerados por parte dos autores com base em observação de campo; e b) validação dos resultados da etapa anterior, mediante pesquisa de opinião com moradores do entorno sobre quais praças frequentavam. As entrevistas foram realizadas no mês de junho de 2017.

Para a primeira etapa, foi elaborada uma ficha de avaliação contendo um conjunto de aspectos que, após os levantamentos, resultaram na nota que constitui o Índice de Atratividade de Praças. Quanto maior essa nota, maior a atratividade, e vice-versa.

A Figura 2 apresenta a estrutura da composição e relacionamento dos atributos, quesitos e itens do Índice de Atratividade de Praças. A composição dos dois atributos, com seus respectivos quesitos e itens é apresentada no Apêndice. 


\section{FIGURA 2: ESTRUTURA DO ÍNDICE DE ATRATIVIDADE DE PRAÇAS}

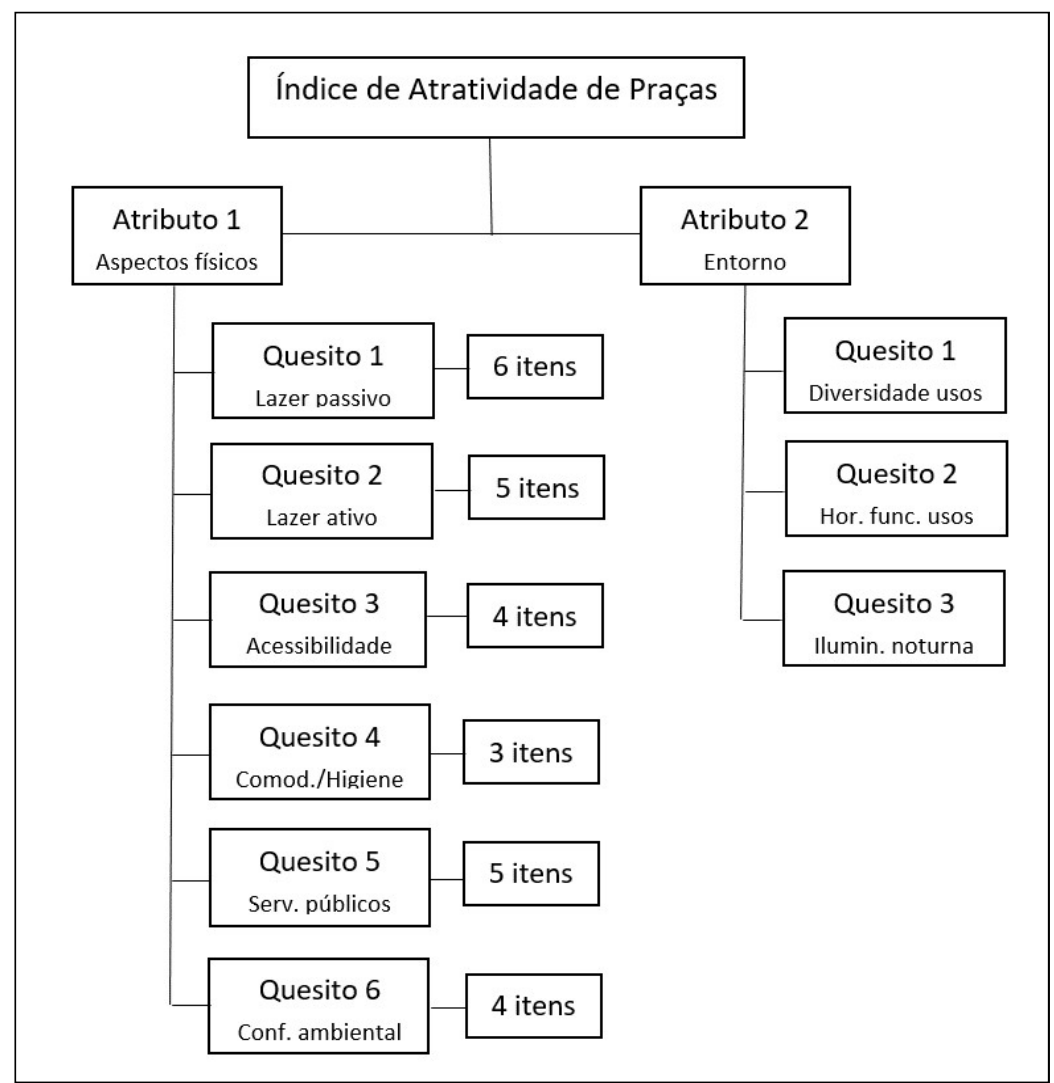

FONTE: Autores.

O índice de atratividade de cada praça é resultado da média aritmética ponderada dos dois atributos, assim especificada: $70 \%$ do Atributo 1, referente às características físicas da praça; e $30 \%$ do Atributo 2, relacionado às características do entorno. Tal ponderação foi estabelecida para dar maior peso às características espaciais da praça e reduzir a influência da pontuação de aspectos relativos ao entorno.

O Atributo 1 (características físicas) engloba os seguintes quesitos: itens de lazer passivo e itens de lazer ativo; acessibilidade a pessoas portadoras de deficiência; nível de desempenho de serviços públicos importantes para o funcionamento da praça; e conforto ambiental. O Atributo 2 se refere às características do entorno e contempla os seguintes quesitos: diversidade de usos do solo; horário de funcionamento dos usos do solo; e iluminação pública.

A disponibilidade de conexões de veículos com a cidade (estacionamento para carros, bicicletário, ponto de táxi, parada de ônibus, etc.), atributo inicialmente cogitado, 
não foi levado em conta porque o público-alvo da pesquisa é constituído pelos moradores do entorno das praças, o que tornou esse atributo irrelevante.

A nota de cada atributo resultou da média geométrica dos seus respectivos quesitos. A média geométrica foi adotada para aumentar a influência do(s) aspecto(s) negativo(s) da praça na média geral. Isso porque, muitas vezes, uma única característica negativa pode ter forte influência na decisão do morador de usar uma determinada praça. Por exemplo, uma praça deficiente em termos de serviços públicos (como coleta de lixo ou policiamento) terá restrições para ser frequentada. Outro exemplo: se uma praça tem usos do solo do entorno que funcionam somente no horário comercial, a frequência ao local poderá ser bastante prejudicada nos outros horários em razão do ambiente pouco movimentado criado por esse entorno. Caso fosse usada a média aritmética, a influência desses aspectos negativos poderia ser mascarada por eventuais bons resultados de outros itens.

Em relação ao Atributo 1, quesitos 1 (lazer passivo) e 2 (lazer ativo), a escolha dos itens componentes de cada quesito foi feita por meio de atribuição de notas a cada item pelos moradores entrevistados. Por sua vez, a pontuação de cada quesito resultou da soma da nota de cada um de seus itens.

Finalmente, a nota geral de cada praça foi calculada pela média ponderada dos dois atributos, com seus respectivos pesos, já mencionados: $70 \%$ para o Atributo 1 (características da praça) e 30\% para o Atributo 2 (características do entorno).

A escolha dos itens componentes dos quesitos 1 (lazer passivo) e 2 (lazer ativo), como visto, foi feita mediante pesquisa de campo com 35 moradores do bairro maiores de 18 anos, residentes em domicílios. Para isso, os autores elaboraram duas listas de elementos com essas finalidades comumente encontrados em praças. Os entrevistados pontuaram cada item presente nas duas listas com base na sua percepção sobre a importância do mesmo: dois pontos se consideravam o item "importante"; um ponto se o achavam "razoavelmente importante"; e zero se o consideravam "sem importância". Ou seja, ao invés de uma lista fechada de itens, previamente definida pelo pesquisador, os moradores puderam fazer a sua própria valoração da importância dos mesmos. Foram mantidos nos resultados de ambos os quesitos apenas aqueles que tiveram pontuação maior ou igual à metade da pontuação do item mais votado, sendo descartados os itens 
que tiveram pontuação menor, com uma margem de tolerância de $-5 \%$ para incluir aqueles que ficaram com pontuação próxima a esse valor.

A escolha dos domicílios para entrevista - um morador por domicílio - foi feita por seleção aleatória sistemática com base no Cadastro de Endereços para Fins Estatísticos, realizado pelo IBGE para o Censo Demográfico 2010, disponível para a parte do bairro da Cidade Velha situado no interior do CHB. Definiram-se inicialmente 50 amostras para alcançar a meta de 35 entrevistas, considerando a possibilidade de haver recusas e domicílios vagos, não encontrados ou que mudaram para usos econômicos. Foram entrevistados 19 mulheres e 16 homens. Ressalte-se que essa amostra, por ter um número reduzido, limitou a presente pesquisa a ser de caráter exploratório.

No segundo momento, as entrevistas com moradores foram usadas como instrumento de validação dos resultados do grau de atratividade das praças estudadas. Para isso, perguntaram-se a esses moradores qual/quais praça(s) frequentavam regulamente. Diante disso, era esperado que aquelas com os maiores índices fossem as mais frequentadas.

Os dados sobre a área aproximada das praças são de responsabilidade dos autores, calculados com recursos disponibilizados do site Google Earth (2018).

\section{RESULTADOS E DISCUSSÕES}

\subsection{ESCOLHA DOS ITENS COMPONENTES DE CADA QUESITO PELOS MORADORES ENTREVISTADOS}

Inicialmente, apresentam-se as escolhas realizadas pelos moradores dos itens dos dois primeiros quesitos do Atributo 1 ("características físicas da praça”). A Figura 3 mostra o resultado da pontuação atribuída pelos entrevistados em valores percentuais da pontuação total. 


\section{FIGURA 3 - AVALIAÇÃO DOS ENTREVISTADOS SOBRE A IMPORTÂNCIA DOS ITENS DE LAZER PASSIVO, EM PERCENTUAL}

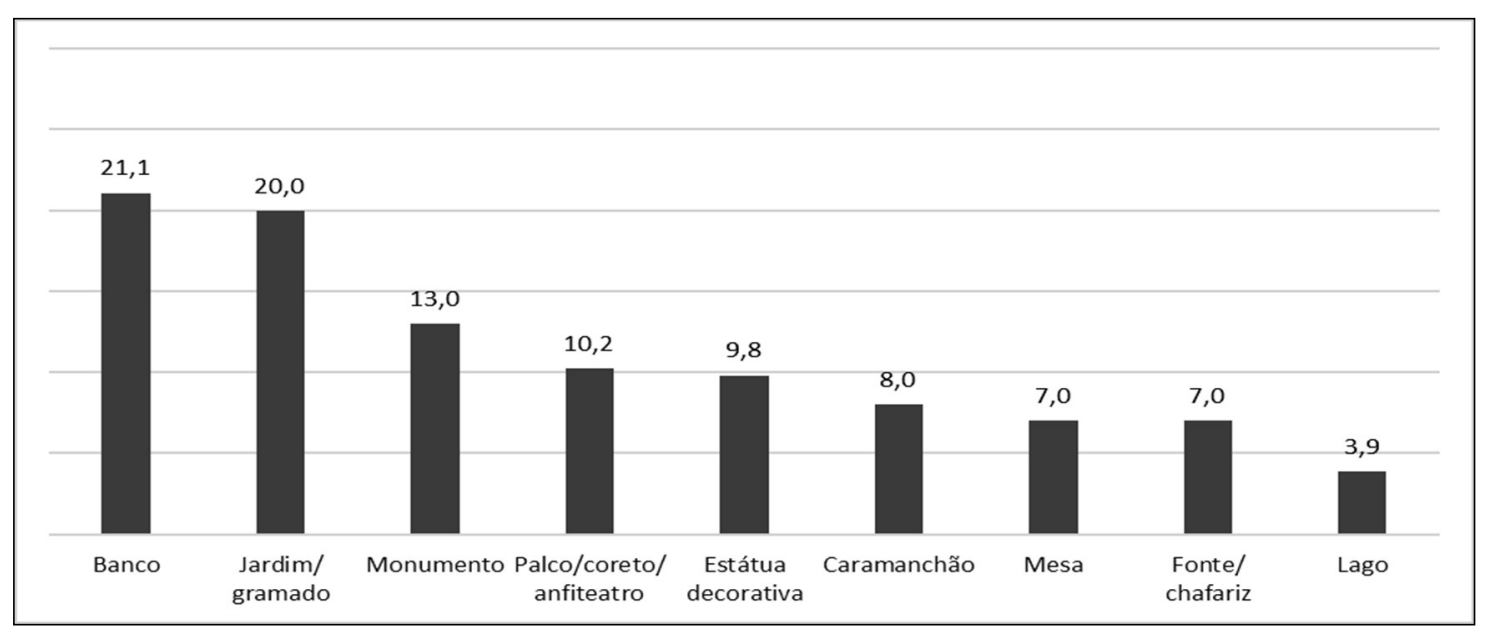

FONTE: Autores.

De acordo com a Figura 3 os itens do Quesito 1 ("lazer passivo") tiveram a seguinte pontuação total dos entrevistados: banco: 60 pontos; jardim: 57; monumento: 37; palco, coreto ou anfiteatro: 29; estátua: 28; caramanchão: 23; mesa: 20; fonte ou chafariz: 20; e lago: 11. Em conformidade com o valor mínimo de seleção adotado para escolha dos itens a serem considerados (metade da pontuação do item mais pontuado, com tolerância de $-5 \%$, como visto), foram excluídos da avaliação técnica do Quesito 1: caramanchão, mesa, fonte ou chafariz e lago.

Ainda que monumento e estátua decorativa tenham permanecido no rol dos itens selecionados, deve-se destacar a pontuação pouco expressiva que tiveram, especialmente este último, que ficou no limiar da pontuação mínima (28 pontos). Isso chama a atenção pelo fato de que as praças situadas em centros históricos abrigam elementos que são de grande relevância para a história e a cultura local. Contudo, a pontuação recebida por esses dois itens revela que nem mesmo os moradores do bairro da Cidade Velha dão grande valor a esses dois elementos no uso cotidiano das praças.

Tal resultado demonstra a necessidade de realizar um trabalho de educação patrimonial voltado aos moradores do bairro, com vistas a destacar o valor dos citados elementos e, dessa forma, aumentar a adesão deles aos esforços de preservação do patrimônio cultural material do local. Isso também é algo importante para enriquecer o aprendizado da cultura local pelos turistas nas suas interações com os moradores. Numa 
perspectiva mais ampla, é um caminho para valorizar elementos importantes da memória coletiva de toda a cidade e, dessa forma, reconstruir a história e a peculiaridade do espaço construído (ROSSI, 2001). Trata-se, enfim, de enriquecer a imagem da cidade contemporânea a partir de elementos presentes nas áreas antigas (ARGAN, 2005).

Adotando-se o mesmo critério de seleção para o Quesito 2 (itens de lazer ativo), foram escolhidos pelos moradores entrevistados todos os itens que constavam na lista formulada pelos autores. A Figura 4 exibe os valores percentuais (em relação ao total da soma dos pontos dos itens) da enquete com os moradores selecionados.

\section{FIGURA 4 - AVALIAÇÃO DOS ENTREVISTADOS SOBRE A IMPORTÂNCIA DOS ITENS DE LAZER ATIVO, EM PERCENTUAL.}

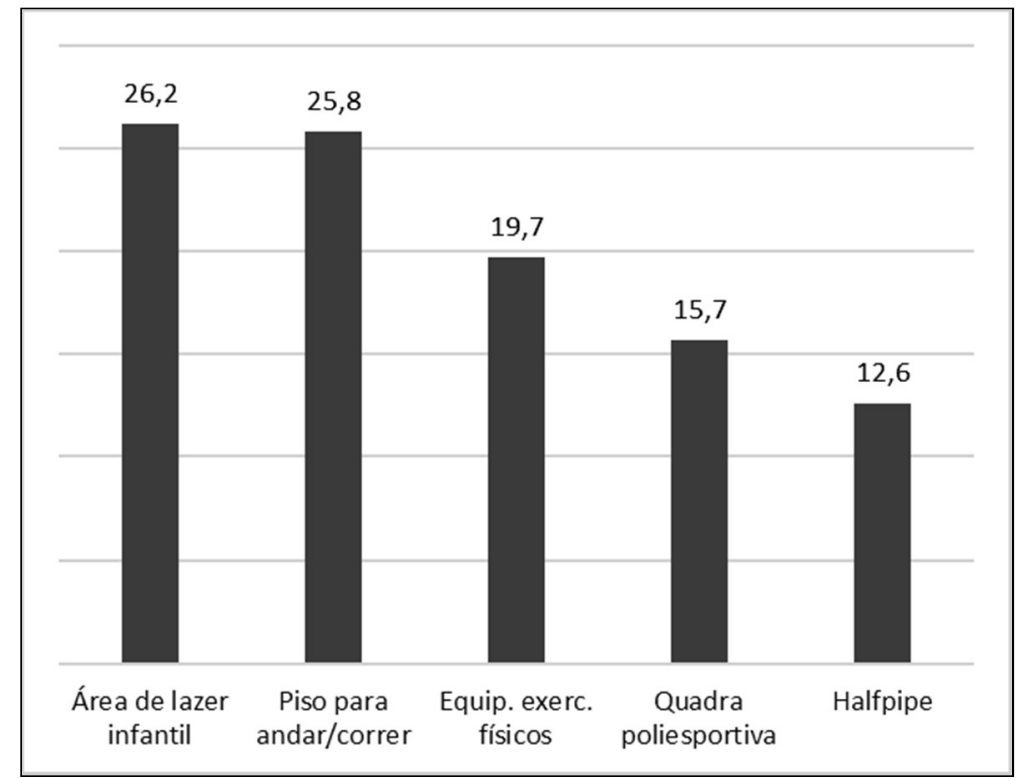

FONTE: Autores.

Os resultados foram os seguintes: área de lazer infantil (52 pontos); piso adequado para andar ou correr (51); equipamentos para exercícios físicos (39); quadra poliesportiva (31); e halfpipe (25). 


\subsection{AVALIAÇÃO TÉCNICA DAS PRAÇAS DO CHB}

A análise dos resultados da avaliação técnica das praças do bairro da Cidade Velha (Tabela 1) mostra que a maior nota ficou com a praça Frei Caetano Brandão, com 5,5 pontos, seguida das praças do Carmo (4,8 pontos), Dom Pedro II $(3,8)$, Filipe Patroni $(3,5)$ e República do Líbano $(3,4)$. Ressalte-se que as pontuações já estão convertidas para a escala de zero a dez.

TABELA 1 - GRAU DE ATRATIVIDADE DE PRAÇAS DO CHB

\begin{tabular}{|c|c|c|c|c|c|c|c|}
\hline \multirow[b]{2}{*}{ Praça } & \multirow[b]{2}{*}{$\begin{array}{l}\text { Média } \\
\text { pond. } \\
\text { (A) } \\
\text { (B) }\end{array}$} & \multicolumn{3}{|c|}{ Atributo 1} & \multicolumn{3}{|c|}{ Atributo 2} \\
\hline & & $\begin{array}{l}\text { Média } \\
\text { geom. } \\
\text { (A) }\end{array}$ & $\begin{array}{c}\text { Quesitos com } \\
\text { maior(es) e } \\
\text { menor(es) } \\
\text { notas }\end{array}$ & Nota & $\begin{array}{l}\text { Média } \\
\text { geom. } \\
\text { (B) }\end{array}$ & $\begin{array}{c}\text { Quesitos com } \\
\text { maior(es) e } \\
\text { menor(es) } \\
\text { notas }\end{array}$ & Nota \\
\hline \multirow{2}{*}{$\begin{array}{c}\text { Frei } \\
\text { Caetano } \\
\text { Brandão }\end{array}$} & \multirow{2}{*}{5,5} & \multirow{2}{*}{4,1} & $\begin{array}{l}\text { Conforto } \\
\text { ambiental }\end{array}$ & 7,5 & \multirow{2}{*}{8,7} & $\begin{array}{c}\text { Diversidade } \\
\text { usos solo } \\
\text { Iluminação } \\
\text { pública }\end{array}$ & 10,0 \\
\hline & & & Lazer ativo & 2,0 & & $\begin{array}{c}\text { Permeabilidade } \\
\text { fachadas } \\
\text { Horário de } \\
\text { funcionamento }\end{array}$ & 7,5 \\
\hline \multirow[t]{2}{*}{ Carmo } & \multirow[t]{2}{*}{4,8} & \multirow[t]{2}{*}{2,8} & $\begin{array}{l}\text { Conforto } \\
\text { ambiental }\end{array}$ & 6,2 & \multirow[t]{2}{*}{9,3} & $\begin{array}{c}\text { Diversidade } \\
\text { usos solo. } \\
\text { Permeabilidade } \\
\text { fachadas } \\
\text { Iluminação } \\
\text { pública }\end{array}$ & 10,0 \\
\hline & & & $\begin{array}{l}\text { Lazer ativo } \\
\text { Serviços } \\
\text { públicos }\end{array}$ & 2,0 & & $\begin{array}{c}\text { Horário de } \\
\text { funcionamento }\end{array}$ & 7,5 \\
\hline \multirow{2}{*}{$\begin{array}{l}\text { Dom } \\
\text { Pedro II }\end{array}$} & \multirow{2}{*}{3,8} & \multirow[t]{2}{*}{2,8} & $\begin{array}{l}\text { Conforto } \\
\text { ambiental }\end{array}$ & 6,2 & \multirow[t]{2}{*}{6,1} & $\begin{array}{l}\text { Iluminação } \\
\text { pública }\end{array}$ & 10,0 \\
\hline & & & Lazer ativo & 1,0 & & $\begin{array}{c}\text { Horário de } \\
\text { funcionamento }\end{array}$ & 2,5 \\
\hline \multirow[t]{2}{*}{$\begin{array}{l}\text { Repúbli } \\
\text { ca do } \\
\text { Líbano }\end{array}$} & \multirow[t]{2}{*}{3,5} & \multirow[t]{2}{*}{2,2} & $\begin{array}{l}\text { Conforto } \\
\text { ambiental }\end{array}$ & 6,2 & \multirow[t]{2}{*}{6,6} & $\begin{array}{c}\text { Diversidade } \\
\text { usos solo } \\
\text { Iluminação } \\
\text { pública }\end{array}$ & 10,0 \\
\hline & & & $\begin{array}{c}\text { Lazer } \\
\text { contemplativo }\end{array}$ & 0,5 & & $\begin{array}{c}\text { Horário de } \\
\text { funcionamento }\end{array}$ & 2,5 \\
\hline \multirow{2}{*}{$\begin{array}{l}\text { Filipe } \\
\text { Patroni }\end{array}$} & \multirow[t]{2}{*}{3,4} & \multirow[t]{2}{*}{2,4} & $\begin{array}{l}\text { Acessibilidade } \\
\text { Conforto } \\
\text { ambiental }\end{array}$ & 5,0 & \multirow[t]{2}{*}{5,5} & $\begin{array}{l}\text { Iluminação } \\
\text { pública }\end{array}$ & 10,0 \\
\hline & & & $\begin{array}{c}\text { Lazer } \\
\text { contemplativo }\end{array}$ & 1,2 & & $\begin{array}{c}\text { Horário de } \\
\text { funcionamento }\end{array}$ & 2,5 \\
\hline
\end{tabular}

FONTE: Autores. 
Nota-se que mesmo a nota mais elevada $(5,5)$ é apenas pouco acima da metade da pontuação total $(10,0)$, o que mostra que as praças do bairro, em geral, possuem reduzida atratividade. Duas praças se destacaram em relação às demais: Frei Caetano Brandão e do Carmo.

Em relação ao Atributo 1 (características físicas), o quesito que mais se destacou por ter as melhores notas nas praças foi o conforto ambiental, algo de grande importância em uma cidade de clima equatorial úmido, onde o calor é elevado na maior parte do dia e as chuvas são frequentes. A presença de árvores de grande porte, especialmente nos locais de maior permanência dos usuários, é de fundamental importância para o adequado sombreamento desses locais.

A influência do estilo eclético, onde a vegetação abundante era um importante princípio projetual, teve influência decisiva sobre esse aspecto. A pontuação mais baixa deste quesito ficou com a praça Filipe Patroni, cuja arborização de porte reduzido limita a capacidade de sombreamento. Nesse sentido, Raskovic e Decker (2015) destacam a influência positiva da presença de árvores na percepção e na permanência de usuários em praças públicas.

Os quesitos que tiveram as piores avaliações nesse atributo foram "lazer passivo" (contemplativo) e "lazer ativo". No caso do primeiro, houve forte influência das más condições de bancos (muitos em estado ruim ou mesmo inutilizados) nas praças Dom Pedro II, do Carmo e Filipe Patroni, e o reduzido número deles na praça República do Líbano.

Quanto ao lazer ativo, o único atrativo que as praças analisadas apresentam é o piso adequado para caminhada ou corrida, o que pode ser explicado pela evolução histórica desses logradouros. Como o paisagismo eclético influenciou a configuração física atual de algumas praças, a caminhada e a corrida constituem as únicas atividades de lazer ativo aí praticadas.

Essa limitação ao lazer ativo pode ser apontada como algo prejudicial ao grau de atratividade das praças e aos potenciais benefícios à saúde que esses espaços poderiam oferecer aos moradores da vizinhança. Koosari, Badland e Giles-Corti (2013) salientam que o aumento da prática de atividades físicas em espaços públicos é uma forma de conectar o desenho urbano com a saúde pública. Santos (2006) destaca a necessidade de 
implantar quadras, academias ao livre ou outros espaços esportivos nas praças - criando espaços multifuncionais que considerem a diversidade de interesses dos usuários. Tal orientação, contudo, entra em conflito com as restrições impostas pelas políticas preservacionistas do espaço construído nos centros históricos, criando uma contradição difícil de resolver.

Agrava esse quadro a deficiente presença governamental na provisão cotidiana de serviços públicos importantes para esses espaços, como coleta de lixo, varrição, policiamento, promoção de eventos, assistência social a mendigos e moradores rua, etc. Este foi outro aspecto em que as todas praças da Cidade Velha tiveram baixas notas.

Registrou-se desempenho pouco favorável também no quesito sobre acessibilidade a pessoas deficientes. O mau estado de conservação de rampas de acesso às praças e a ocorrência de problemas de conservação dos pavimentos foram os principais fatores para isso.

Em relação ao Quesito 2 (características do entorno), os destaques ficaram por conta das praças do Carmo (9,3 pontos) e Frei Caetano Brandão $(8,7)$. Em patamares bem inferiores ficaram as praças República do Líbano $(6,6)$, Dom Pedro II $(6,1)$ e Filipe Patroni $(5,5)$. Se a iluminação pública adequada foi um fator positivo em todas elas, o horário de funcionamento das atividades do entorno apenas no horário comercial foi decisivo para reduzir as notas nas três últimas.

O bom desempenho da praça do Carmo em relação ao seu entorno se explica tanto pela grande variedade de atividades como pelo seu funcionamento em diferentes horários: residências, escola, igreja, lojas, bares, proximidade de um terminal de transporte fluvial de passageiros e um núcleo de pesquisa e extensão da Universidade Federal do Pará, o que configura um entorno com grande vitalidade no sentido atribuído a esse termo por Jacobs (2011), Gehl (2013) e Bentley et al. (1999).

Já a praça Frei Caetano Brandão, ainda que tenha poucos domicílios no seu entorno, é cercada por atividades econômicas que também funcionam em vários horários - museus, restaurantes, bares, lojas e igreja, dentre outros -, além de ser bastante procurada por turistas. As demais praças estudadas estão cercadas principalmente por atividades institucionais e comerciais com funcionamento restrito ao período diurno, o que justifica as baixas notas obtidas por elas neste quesito. 


\subsection{FREQUÊNCIA DE USO DAS PRAÇAS DO CHB}

Outro resultado da pesquisa obtido com as entrevistas feitas com uma amostra de 35 moradores, destinadas a identificar as praças que eram frequentadas pelos informantes (podendo ser mais de uma praça).

Mais da metade dos entrevistados (55\%) respondeu que frequentava a Praça Frei Caetano Brandão; 41\%, a Praça do Carmo; 15\%, a Praça República do Líbano; 11\%, a Praça Filipe Patroni; e somente 5\%, a Praça Dom Pedro II. Portanto, as duas praças com as maiores pontuações do Índice de Atratividade de Praças foram justamente aquelas referidas pelos entrevistados com as que mais frequentavam.

Com a ressalva de ser uma pesquisa de caráter exploratório pelo reduzido tamanho da amostra, os resultados, em geral, corroboraram o levantamento técnico, sendo um indicativo de que o Índice de Atratividade de Praças pode constituir um instrumento válido para avaliar o quanto esses locais são espaços públicos favoráveis ao usufruto dos moradores das redondezas.

\section{CONCLUSÃO}

Os resultados da pesquisa mostraram que o Índice de Atratividade de Praças, aqui proposto, pode ser um instrumento interessante para uma avaliação quantitativa desses espaços públicos. Este índice constitui, assim, uma contribuição para a literatura sobre a avaliação quantitativa de fatores que influenciam os moradores de um local a fazer uso de praças e, dessa forma, torná-las locais movimentados e com oportunidades para interação entre residentes e turistas.

As praças do Centro Histórico de Belém apresentaram fraco desempenho em geral, principalmente em relação à atividade mais importante aí realizada: o lazer. A configuração física das praças limita a prática de atividades de lazer ativo. Por outro lado, as restrições de caráter preservacionista impõem dificuldades à adequação das mesmas a práticas esportivas e outras formas de lazer ativo. A esses problemas se acrescem os relacionados à deficiente manutenção desses espaços públicos. 
Já outra característica do paisagismo eclético, a arborização abundante, contou favoravelmente no quesito conforto ambiental com exceção da Praça Filipe Patroni, onde a vegetação é de pequeno porte. Num clima equatorial quente e úmido como da cidade de Belém, essa característica favorece o uso da praça.

Vale destacar que o crescente abandono do espaço público reforça a sensação de insegurança relacionada à criminalidade, aumentando a importância de dois aspectos tratados neste trabalho. O primeiro é o policiamento adequado nas praças. O segundo é a importância da vitalidade do entorno nos diversos horários do dia. Neste aspecto, as cinco praças estudadas configuram duas situações bem diferenciadas. No caso das praças D. Pedro II, Filipe Patroni e República do Líbano, a reduzida vitalidade do entorno fora do horário comercial coloca um problema de difícil equacionamento para sua utilização mais intensa. A realização sistemática de eventos pelo poder público - por exemplo, atividades físicas orientadas por profissionais competentes - pode ser uma alternativa para minimizar o problema.

A intensificação do uso das praças e outros espaços públicos, especialmente nos centros históricos, representa um importante desafio a ser enfrentado pela gestão urbana na perspectiva de moradores e turistas. Isto porque ocorre, nesses locais, a presença significativa de elementos de elevado valor histórico e cultural nesses locais, bem como a possibilidade de os turistas entrarem em contato com a população local. Todavia, é de fundamental importância que as ações do poder público voltadas para estimular a presença de turistas nas áreas públicas não conflitem com os interesses dos moradores em usufruir esses locais em conformidade com a sua cultura e suas tradições.

Ressalte-se que uma limitação desta pesquisa é não ter entrevistado turistas, considerando que o foco do trabalho é investigar a capacidade de cada praça para atrair moradores. Dessa forma, buscou-se avaliar seu potencial turístico não apenas sob o aspecto físico ou cultural, como também como local propício para conhecimento do modo de vida dos residentes.

Nesse contexto, o Índice de Atratividade de Praças (IAP) pode constituir um instrumento útil para avaliar o potencial de atração de usuários de uma praça. Tal constatação coloca a necessidade de realizar investigações específicas sobre o potencial das praças como locais de oportunidade para que os visitantes conheçam melhor o modo de vida dos moradores. 


\section{REFERÊNCIAS}

ARGAN, G. C. História da arte como história da cidade. 5. ed. São Paulo: Martins Fontes, 2005.

BELÉM. Lei n. 7.709, de 18 de maio de 1994. Dispõe sobre a preservação e proteção do patrimônio histórico, artístico, ambiental e cultural do município de Belém e dá outras providências. Diário Oficial [do Município de Belém], 1994.

BELÉM. Lei Orgânica do Município de Belém, de 30 de março de 1990. Diário Oficial [do Município de Belém], 1990.

BENTLEY, I.; ALCOCK, A.; MCGLYNN, S.; MURRAIN, P.; SMITH, G. Entornos vitales: hacia un diseño urbano y arquitectónico más humano - manual práctico. Barcelona: Gustavo Gili, 1999.

BRASIL. Lei $\mathrm{n}^{\mathrm{o}}$. 10.048, de 8 de novembro de 2000. Estabelece normas gerais e critérios básicos para a promoção da acessibilidade das pessoas portadoras de deficiência ou com mobilidade reduzida, e dá outras providências. Diário Oficial [da República Federativa do Brasil]. Brasília, DF, 20 dez. 2000, p. 2. Disponível em:

https://www2.camara.leg.br/legin/fed/lei/2000/lei-10098-19-dezembro-2000-377651publicacaooriginal-1-pl.html. Acesso em: 3 set. 2019.

BRASIL. Ministério da Infraestrutura. Secretaria Nacional de Aviação Civil.

Comparativo anual da movimentação de passageiro. Disponível em:

https://horus.labtrans.ufsc.br/gerencial/\#Movimentacao/Comparativo Acesso em: 30/07/2019.

CALDEIRA, J. M. A praça colonial brasileira. Arquitetura e Comunicação Social, v. 7, n. 1, p. 19-39, 2010. Disponível em:

https://www.publicacoesacademicas.uniceub.br/arqcom/article/view/1113 . Acesso em: 20/10/2017.

CASTRO, A. Espaços públicos, coexistência social e civilidade contributos para uma reflexão sobre os espaços públicos urbanos. Cidades: Comunidades e Territórios, $\mathrm{n}$. 5, p. 53-67, 2002. Disponível em: https://repositorio.iscte-iul.pt/handle/10071/3392. Acesso em: 20/09/2017.

DE ANGELIS, B. L. D., CASTRO, R. M.; DE ANGELIS NETO, G. Metodologia para levantamento, cadastramento, diagnóstico e avaliação de praças no Brasil. Engenharia Civil, v. 4, n. 1, p. 57-70, 2004. Disponível em:

http://www.civil.uminho.pt/revista/artigos/Num20/Pag\%2057-70.pdf . Acesso em: 01/10/2017.

FAPESPA (FUNDAÇÃO AMAZÔNIA DE AMPARO A ESTUDOS E PESQUISAS).

Boletim de turismo do estado do Pará. Belém, 2017. Disponível em:

http://www.setur.pa.gov.br/sites/default/files/pdf/boletim_do_turismo_2017.pdf. Acesso 
em: 28/07/2019.

FRANCIS, J.; WOOD, L. J.; KNUIMAN, M.; GILES-CORTI, B. Quality or quantity? Exploring the relationship between Public Open Space attributes and mental health in Perth, Western Australia. Social Science \& Medicine, v. 74, n. 10, p. 1570-1577, 2012. Disponível em: https://www.ncbi.nlm.nih.gov/pubmed/22464220 . Acesso em: 27/10/2017.

GEHL, J. Cidades para pessoas. São Paulo: Perspectiva, 2013.

GOOGLE EARTH. https://www.google.com.br/earth/. 2018.

IBGE (INSTITUTO BRASILEIRO DE GEOGRAFIA E ESTATÍSTICA). Censo demográfico 2010. Rio de Janeiro, 2010.

ISMAGILOVA, G.; SAFIULLIN, L.; GAFUROV, I. Using historical heritage as a factor in tourism development. Procedia - Social and Behavioral Sciences, v. 188, n. 14, p. 157-162, 2015. Disponível em:

https://www.sciencedirect.com/science/article/pii/S1877042815021485. Acesso em: 28/07/2019.

JACOBS, J. Morte e vida de grandes cidades. 3. ed. São Paulo: Martins Fontes, 2011.

KOOSARI, M. J.; BADLAND H.; GILES-CORTI, B. (Re)Designing the built environment to support physical activity: Bringing public health back into urban design and planning. Cities, n. 35, p. 294-298, 2013. Disponível em:

https://www.sciencedirect.com/science/article/pii/S0264275113000978?via\%3Dihub . Acesso em: 09/12/2017.

LAMAS, J. M. R. G. Morfologia urbana e desenho da cidade. Lisboa: Fundação Calouste Gulbenkian, 1993.

MACHADO, S. F.; ALVES, K. S. O turismo em Ouro Preto - Minas Gerais, Brasil - na perspectiva dos moradores. Turismo e Sociedade, v. 6, n. 3, p. 552-573, jul. 2013. Disponível em: https://revistas.ufpr.br/turismo/article/view/30888 . Acesso em: 10/11/2017.

MEHAN, A. Investigating the role of historical public squares on promotion of citizen's quality of life. Procedia Engineering, v. 161, p. 1768-177, 2016. Disponível em: https://www.sciencedirect.com/science/article/pii/S187770581633003X . Acesso em: 05/11/2017.

RASKOVIC, S.; DECKER, R. The influence of trees on the perception of urban squares. Urban Forestry \& Urban Greening, v. 14, n. 2, p. 237-245, 2015. Disponível em: https://www.sciencedirect.com/science/article/pii/S1618866715000102 . Acesso em: 05/11/2017. 
REIS FILHO, N. G. Contribuição ao estudo da evolução urbana do Brasil: 15001720. 2. ed. São Paulo: Pini, 2000.

ROBBA, F.; MACEDO, S. S. Praças brasileiras. São Paulo: Edusp, 2003.

ROSSI, A. A arquitetura da cidade. São Paulo: Martins Fontes, 2001.

SANTOS, P. F. Formação de cidades no Brasil colonial. Rio de Janeiro: UFRJ, 2001.

SANTOS, E. S. Reflexões sobre a utilização de espaços públicos para o lazer esportivo.

Revista Ra'e Ga - O Espaço Geográfico em Análise, n. 11, p. 25-33, 2006.

Disponível em: https://revistas.ufpr.br/raega/article/view/7745 . Acesso em: 10/11/2017.

SARGES, M. N. Belém: riquezas produzindo a Belle-Époque (1870-1912). 3. ed. Belém: Paka-Tatu, 2010.

SEGAWA, H. Ao amor do público: jardins no Brasil. São Paulo: Studio Nobel: FAPESP, 1996.

SITTE, C. A construção das cidades segundo seus princípios artísticos. São Paulo: Ática, 1992.

SOARES, E. N. Largos, coretos e praças de Belém. Brasília, DF, Instituto do Patrimônio Histórico e Artístico Nacional, 2009.

SOBRAL, M. L. S. Os guardiões da memória na Praça D. Pedro II. 108 p.

Dissertação (Mestrado em Antropologia), Universidade Federal do Pará, Belém, 2006.

THOMPSON, C. W. Urban open space in the 21 st century. Landscape and Urban Planning, v. 60, n. 2, p. 59-72, 2002. Disponível em: https://www.sciencedirect.com/science/article/pii/S0169204602000592?via\%3Dihub . Acesso em: 06/11/2017.

VILLAÇA, F. O espaço intra-urbano no Brasil. São Paulo: Studio Nobel, 2001.

WOOD, L.; HOOPER, P.; FOSTER, S.; BULL, F. Public green spaces and positive mental health - investigating the relationship between access, quantity and types of parks and mental wellbeing. Health \& Place, v. 48, p. 63-71, Nov. 2017. Disponível em: https://www.ncbi.nlm.nih.gov/pubmed/28942343. Acesso em: 12/11/2017.

ZAKARIYA, K.; HARUN, N. Z. MANSOR, M. Place meaning of the historic square as tourism attraction and community leisure space. Procedia - Social and Behavioral Sciences,v. 202, n. 22, p. 477-486, Aug. 2015. Disponível em: https://www.sciencedirect.com/science/article/pii/S1877042815048442. Acesso em: 27 jul. 2019. 


\section{APÊNDICE 1: COMPONENTES DO ÍNDICE DE ATRATIVIDADE DE PRAÇAS}

1) ATRIBUTO 1: características físicas da praça.

a) Quesito 1: lazer passivo, composto por itens ligados a lazer contemplativo e interação social. A escolha dos itens deste quesito foi resultado de enquete com os moradores selecionados, como mencionado. A nota final resulta da soma das notas parciais dos itens a seguir.

i) Banco, cujo cálculo considerou o estado de conservação das várias unidades existentes na praça, sendo a pontuação final assim calculada: quantificação do número de itens nos três estados de conservação considerados (inutilizado, ruim ou bom); multiplicação do número de itens em de cada estado de conservação por um fator relativo a este estado $(0,1$ para as unidades inutilizadas; 0,5 para aquelas em estado ruim; e 1 para a que estavam em bom estado, números estes que se justificam pela possibilidade dos itens inutilizados serem consertados e os em estado ruim serem usados parcialmente);

ii) Monumento, com o mesmo procedimento de cálculo do item anterior;

iii) Estátua decorativa, idem;

iv) Palco, coreto ou anfiteatro, idem;

v) Jardim ou gramado, idem.

b) Quesito 2: lazer ativo. A exemplo do anterior, a escolha dos itens deste quesito foi resultado de enquete com os moradores selecionados.

i) Quadra poliesportiva, com o mesmo procedimento de cálculo do item anterior;

ii) Equipamentos para exercícios físicos, idem;

iii) Área de lazer infantil, idem;

iv) Halfpipe, idem; e

v) Piso adequado para andar ou correr, idem.

c) Quesito 3: acessibilidade a pessoas portadoras de deficiência

i) Rampas (de acesso e internas) para cadeirantes, idem;

ii) Piso adequado para cadeirantes, idem;

iii) Área de lazer ativo para pessoas deficientes, idem; 
iv) Banheiro público adaptado para pessoas deficientes, idem.

d) Quesito 4: comodidade e higiene. Decidiu-se não incluir o item "telefone público" em razão da larga difusão da telefonia celular.

i) Lixeiras

ii) Sanitário público

iii) Quiosque de alimentação

e) Quesito 5: serviços públicos

i) Coleta de lixo, cujo cálculo considerou o nível de presença e desempenho do serviço praticado na praça, sendo a pontuação final do item constituída por uma média ponderada dos seguintes pesos para as seguintes avaliações do serviço: 0 para ausente; 0,5 para deficiente; e 1 para adequado;

ii) Varrição, idem item anterior;

iii) Policiamento, idem;

iv) Eventos para estímulo ao lazer e atividades físicas; e

v) Assistência social a mendigos e moradores de rua, idem.

f) Quesito 6: conforto ambiental

i) Equilíbrio entre sombreamento e insolação, que considerou o nível de adequação do item na praça, sendo a pontuação final do item constituída por uma média ponderada dos seguintes pesos para as seguintes avaliações: 0,0 para inadequado; 0,5 para razoável; e 1 para bom;

ii) Ventilação, idem;

iii) Iluminação noturna, idem;

iv) Nível de ruído.

\section{2) ATRIBUTO II: Características do entorno}

O Atributo 2 diz respeito às características do entorno, algo considerado de suma importância para o grau de atratividade das praças. Este atributo é composto pelos seguintes quesitos, com suas respectivas pontuações:

a) Quesito 1: diversidade de usos do solo, com a seguinte pontuação:

i) Somente um tipo de uso do solo: 1 ponto.

ii) Dois tipos de usos do solo: 2 pontos.

iii) Três tipos de usos do solo: 3 pontos. 
iv) Quatro ou mais usos do solo: 4 pontos.

b) Quesito 2: horário de funcionamento dos usos do solo do entorno.

i) Totalidade dos imóveis apenas no horário comercial: 1 ponto.

ii) Mais da metade apenas no horário comercial e menos da metade também em outros horários: 2 pontos.

iii) Menos da metade apenas no horário comercial e mais da metade também em outros horários: 3 pontos.

iv) Totalidade em horário comercial e também outros horários: 4 pontos.

c) Quesito 3: iluminação pública.

i) Iluminação adequada em até $1 / 4$ do entorno: 1 ponto.

ii) Iluminação adequada em mais de $1 / 4$ a $1 / 2$ do entorno: 2 pontos.

iii) Iluminação adequada em mais de $1 / 2$ a 3/4 do entorno: 3 pontos.

iv) Iluminação adequada em mais de $3 / 4$ do entorno: 4 pontos.

Recebido em: 04-06-2019.

Aprovado em: 14-09-2019.

Versão aprovada para publicação em: 15-09-2019. 